\title{
Effect of the Host and Temperature on the Formation of Defective RNAs Associated with Broad bean mottle virus Infection
}

\author{
Susana Llamas, Claudio Sandoval, Mar Babin, Judy Pogany, Jozef J. Bujarski, and Javier Romero
}

First, second, third, and sixth authors: Departamento de Protección Vegetal, INIA, Autopista A-6, Km. 7.0 28040- Madrid, Spain; fourth and fifth authors: Plant Molecular Biology Center, Department of Biological Sciences, Northern Illinois University, DeKalb 60115; and fifth author: Institute of Bioorganic Chemistry, Polish Academy of Sciences, Poznan, Poland.

Current address of C. Sandoval: Universidad de Talca, Escuela de Agronomía, Casilla 747, Talca, Chile.

Current address of J. Pogany: University of Kentucky, Department of Plant Pathology, Lexington 40546.

Accepted for publication 18 August 2003.

\begin{abstract}
Llamas, S., Sandoval, C., Babin, M., Pogany, J., Bujarski, J. J., and Romero, J. 2004. Effect of the host and temperature on the formation of defective RNAs associated with Broad bean mottle virus infection. Phytopathology 94:69-75.

Previously, we demonstrated that Broad bean mottle virus (BBMV), a member of the genus Bromovirus, could accumulate RNA 2-derived defective interfering (DI) RNAs during infection. In this work, we study how host and environmental factors affect the accumulation of DI RNAs. Serial passages of BBMV through selected plant species reveal that, with low-multiplicity inocula, some systemic hosts (Vicia faba, Nicotiana

sativum, and Glycine max) do not. However, several passages with the high-multiplicity inocula can generate DI RNAs in pea plants. Local lesion hosts (Chenopodium quinoa, C. amaranticolor, and C. murale) remain free of the DI RNA components. The size of the de novo-formed DI RNAs depends on the host and on environmental conditions. For instance, broad bean plants cultivated in a greenhouse or in a growth chamber at $20^{\circ} \mathrm{C}$ accumulated DI RNAs of 2.4 or $1.9 \mathrm{~kb}$ in size, respectively. A reverse trend was observed in pea plants. Lower temperatures greatly facilitated the formation of DI RNAs in broad bean and pea hosts after the first passage. The importance of these findings for the studies on DI RNAs are discussed.
\end{abstract} clevelandii, and N. tabacum cv. Samsum) support DI RNA accumulation after the first passage cycle but other hosts (Phaseolus vulgaris, Pisum
Additional keywords: bromoviruses, host effects, temperature conditions.
Defective interfering (DI) RNAs often are associated with plant viral infections, and are derived from the viral RNA genome by further deletions or rearrangements $(6,21)$. The accumulation of DI RNAs depends not only upon the initial generation event (14) but also on structural factors such as the presence of replication signals, the overall size, and the coding capacity that were found to influence the levels of the types of defective RNA molecules of Turnip crinkle virus (TCV) DI RNAs (15) and Clover yellow mosaic virus (CYMV) $(24,25)$.

Broad bean mottle virus (BBMV), in the family Bromoviridae (12), has a tripartite, single-stranded messenger-sense RNA genome. RNAs 1 and 2 encode the replicase proteins, 1a and 2a, respectively $(5,19)$, while the dicistronic RNA 3 encodes the movement protein (designated $3 \mathrm{a}$ ) and the coat protein. The latter protein is expressed from subgenomic RNA $4(5,19)$. Full-length cDNA clones from which infectious RNAs can be synthesized are available for four BBMV strains (16). Unlike other bromoviruses, wild-type (wt) BBMV RNAs have an unusual 5' end cap structure (GpppA) (5,19). Nevertheless, in vitro transcripts bearing the GpppG (to facilitate the efficient initiation of T7 RNA polymerase on cDNA templates) are infectious, but the correct $5^{\prime}$ termini are restored during infection (16). BBMV RNA transcripts barely replicate in Nicotiana benthamiana protoplasts, and do not replicate in either barley, broad bean, or N. tabacum nc. Xanthi protoplasts (16).

Corresponding author: J. Romero; E-mail address: Romero@inia.es

S. Llamas and C. Sandoval contributed equally to this work.

Publication no. P-2003-1024-02R

(C) 2004 The American Phytopathological Society
Previously, we characterized several RNA 2-derived DI RNAs of BBMV that were obtained from field isolates or from plants grown in a greenhouse (20). Some of the DI RNAs also were generated de novo by serial passages of DI RNA-free BBMV isolates through broad bean plants (17). Most of these DI RNAs were unique; however, they showed some common features, such as retention of the $5^{\prime} 1,152$ and the $3^{\prime} 468$ nucleotides (nt) of flanking sequences of wt RNA 2. The total length of the DI RNAs ranged between 2,053 and 2,476 nt, and the translation capability was preserved in all characterized DI RNAs. The ability to interfere with the accumulation of the helper virus was demonstrated for two predescribed DI RNA species (20).

Several preliminary observations suggested that, besides structural features, the type of host and growing conditions could affect the accumulation of DI RNAs (20). In this work, we confirm that some hosts can support efficient accumulation of DI RNAs, whereas others cannot. We also show that serial passages at high multiplicity of infection can facilitate de novo formation of DI RNAs in the originally nonpermissive hosts. We confirm that size of the accumulating DI-RNAs depends on the environment and on the host and, most interestingly, the DI-RNAs are formed preferably at lower temperatures.

\section{MATERIALS AND METHODS}

BBMV strains, plant inoculations, and growing conditions. The type strain of BBMV was provided by P. Kaesberg (Institute for Molecular Virology, Madison, WI). The Morocco (Mo) strain of BBMV was a gift from K. M. Makkouk (ICARDA, Syria). The strains were maintained by mechanical inoculation in broad bean (Vicia faba cv. Lincoln). Production of RNA transcripts with T7 RNA polymerase and plant inoculations were done as described 
by Pogany et al. (18). Plants were grown in the greenhouse with variation in temperature of $22 \pm 5^{\circ} \mathrm{C}$, or in a growth chamber with $16 \mathrm{~h}$ of light and a constant temperature.

Virus passages. Broad bean and pea plants in a two-leaf state were co-inoculated with a DI RNA-free virion RNA preparation of the helper virus (obtained from plants inoculated with the transcribed genomic RNAs of the type strain of BBMV). We used 15 plants in each treatment and at least three repetitions were made for each experiment. As positive control, broad bean and pea plants were co-inoculated with DI RNA-free virion RNA plus the in vitro transcribed artificial DI RNAs that were derived from the RNA 2 component of the Mo strain.

RNA analyses and reverse-transcription polymerase chain reaction. Virion RNAs were extracted from systemically infected leaves of each plant 2 weeks postinoculation, after virus purification, according to Romero et al. (20). Virion RNAs were tested either by northern blot hybridization according to Kroner et al.

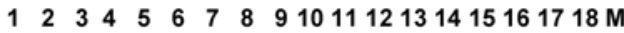

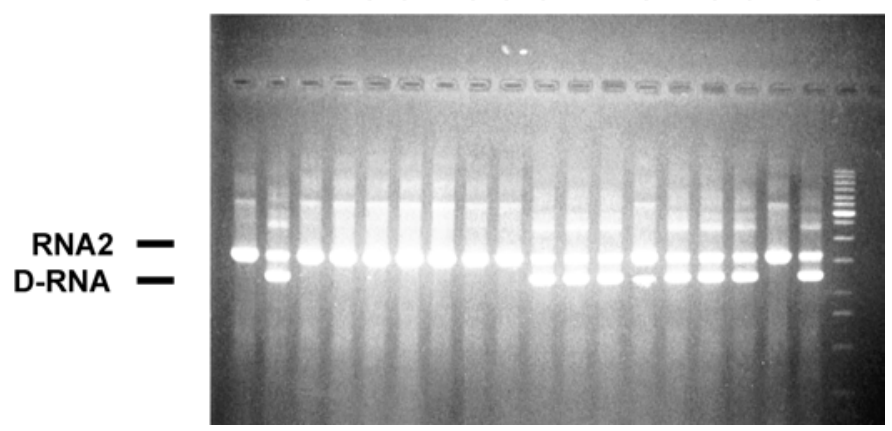

Fig. 1. Electrophoretic analysis of the accumulation of defective interfering (DI) RNAs in different Broad bean mottle virus (BBMV)-infected host plants. Plants that were inoculated with the DI RNA-carrying virus (Morocco strain) originated from broad bean plants with the RNA extracted 10 days after inoculation. Total RNA was extracted and the RNA 2-specific sequences were amplified by reverse-transcription polymerase chain reaction with primers 58 and 170 and separated in a 1.5\% agarose gel. Lanes contained the following samples: 1, control BBMV RNAs without DI RNAs; 2, control BBMV RNAs with DI RNAs; 3, Chenopodium quinoa; 4, C. amaranticolor; 5, C. murale; 6, C. hybridum; 7, Phaseolus vulgaris; 8, Glycine max; 9, Pisum sativum; 10, Vicia faba; 11, Nicotiana tabacum cv. Samsun; 12, N. tabacum cv. Turkish; 13, N. tabacum cv. Xanthi; 14, N. clevelandii; $15, N$. benthamiana; $16, N$. glutinosa; $17, N$. occidentalis; $18, N$. rustica; and M, 1-kb marker (Biotools, Madrid, Spain).
(11), using an $\left(\alpha_{-}{ }^{32} \mathrm{P}\right) \mathrm{rCTP}$ or dioxigenine-labeled RNA probe, that was complementary to nucleotides 39 to 461 of BBMV RNA 2 , or by reverse-transcription polymerase chain reaction (RTPCR), as described by Romero et al. (20).

The following deoxyoligonucleotide primers were used in the RT-PCR reactions: 5'-GCGCGGATCCAAGCGGTGATTATG-3' (primer 90, specific for Mo RNA 2) with a BamHI restriction site (underlined), corresponding to nucleotide positions 2,681 to 2,694 in Mo RNA 2 (first-strand primer) and the second-strand primers, either 5'-TATCGAAGCTTATAAGTGTAGAATCGAGG-3' (primer 37; HindIII site underlined) corresponding to the very $5^{\prime}$ end of the RNA 2, 5'-TATCGAAGCTTGCGTCTATAGAGAGTTTAGAGGC-3' (primer 58, HindIII site underlined), corresponding to nucleotide positions 845 to 867 in Mo RNA 2, or 5'GAGGGGATCCGCTCATCACGGTCGTCACG-3' (primer 170, BamHI site underlined), corresponding to nucleotide positions 2,426 to 2,444 in Mo RNA 2. The cDNA products were cloned as described by Pogany et al. (17).

\section{RESULTS}

Accumulation of DI RNAs in different BBMV hosts. To determine which of the BBMV host plants can maintain BBMV DI RNAs, 16 different plant species were inoculated with a DI RNAbearing BBMV inoculum from broad bean plants (Fig. 1). The following BBMV local lesion hosts did not accumulate DI RNAs: Chenopodium quinoa (lane 3), C. amaranticolor (lane 4), C. murale (lane 5), and $C$. hybridum (lane 6). Likewise, several systemically infected hosts, including Phaseolus vulgaris (lane 7), Glycine max (lane 8), Pisum sativum (lane 9), and N. occidentalis (lane 17) did not accumulate DI RNAs. In contrast, the following BBMV systemically infected hosts supported high levels of DI RNAs: N. tabacum cv. Xanthi (lane 13), N. tabacum cv. Samsun (lane 11), N. tabacum cv. Turkish (lane 12), N. clevelandii (lane 14), N. benthamiana (lane 16), N. rustica (lane 18), and $N$. glutinosa (lane 16).

De novo formation and accumulation of BBMV DI RNAs in pea and in broad bean. Previously, we demonstrated that BBMV DI RNAs could be formed de novo after several passages of BBMV infection through broad bean plants by using a high concentration of viral inoculum (17). On the other hand, we observed that pea plants did not support the DI RNAs after passages from broad bean when using low-concentration viral inocula (20).

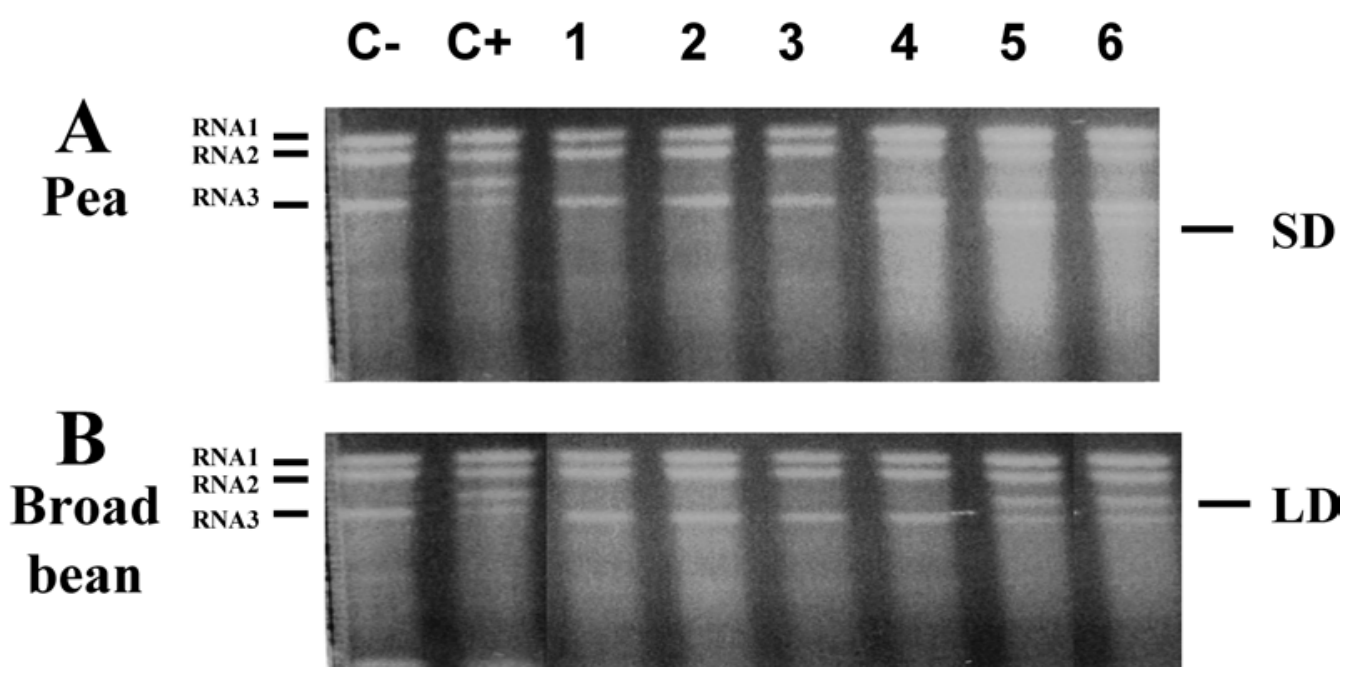

Fig. 2. Detection of de novo-generated Broad bean mottle virus (BBMV) defective interfering (DI) RNAs after serial passages in A, pea or B, broad bean plants. Seedlings were inoculated with BBMV-RNA free of DI RNAs (obtained from plants inoculated with the transcribed genomic RNAs of BBMV) and maintained in a greenhouse. At 10 days after inoculation, the encapsidated viral RNA was purified and inoculated onto new plants. The encapsidated RNA was analyzed after each passage by electrophoresis in a 1\% agarose formamide-formaldehyde denaturing gel. Lanes contained the following samples: C-, BBMV RNA without DI RNAs; and C+, BBMV RNA with large 2.4-kb DI RNA (LD). Lanes 1 to 6 indicate the subsequent passages. The accumulation of small (SD) and LD DI RNAs is visible in A, lanes 4 to 6 and $\mathbf{B}$, lanes 5 to 6 , respectively. 
To continue these studies and to observe if pea plants could support different kinds of DI RNAs, BBMV infection was passaged four times through pea seedlings (cv. Lincoln) and, in a parallel experiment, the same virus was passaged five times through broad bean plants under greenhouse conditions. The RNA was extracted after each passage and analyzed electrophoretically. The first three passages through pea (Fig. 2A, lanes 1 to 3 ) and the first four passages through broad bean (Fig. 2B, lanes 1 to 4), did not reveal the presence of DI RNAs. However, after the fourth passage in pea or the fifth passage through broad bean, additional DI RNA bands emerged (lanes 4 to 6 and 5 to 6 , respectively). Interestingly, the size of the DI RNA in pea was different than that in broad bean (1,900 and 2,400 nt, respectively). The small DI RNAs were designated as SD RNAs and the large DI RNAs as LD RNAs to indicate being smaller or larger, respectively, than wt RNA 3.

To determine whether one kind of DI RNAs accumulated in pea or in broad bean hosts, the above new DI RNAs were amplified by RT-PCR with a pair of BBMV RNA 2-specific oligonucleotide primers 58 and 170, and the cDNA products were cloned and sequenced. The accumulating DI RNAs shared the characteristics of previously described BBMV DI RNAs: a large central deletion, conservation of the $5^{\prime}$ and $3^{\prime}$ extremes, maintenance of the open reading frame of $2 \mathrm{a}$ protein, and a larger-than-RNA 3 length in broad bean (Fig. 2B). The analysis of 10 cDNA clones demonstrated the accumulation of one type of DI RNA molecules in either pea or in broad bean hosts (data not shown).

Effect of growing conditions on the accumulation and systemic movement of BBMV DI RNAs in pea and broad bean. Two sets of 15 BBMV-infected pea or broad bean plants were maintained in a growth chamber at $20^{\circ} \mathrm{C}$ with $16 \mathrm{~h}$ of light, or in a greenhouse, where the temperature varied according to weather conditions; at least three repetitions were made at different periods during the year. After five passages (Fig. 3A, upper panels), the infected broad bean plants accumulated the LD DI RNA when grown in a greenhouse (Fig. 3A, lanes 2 to 5, left panel); whereas,

A

Greenhouse
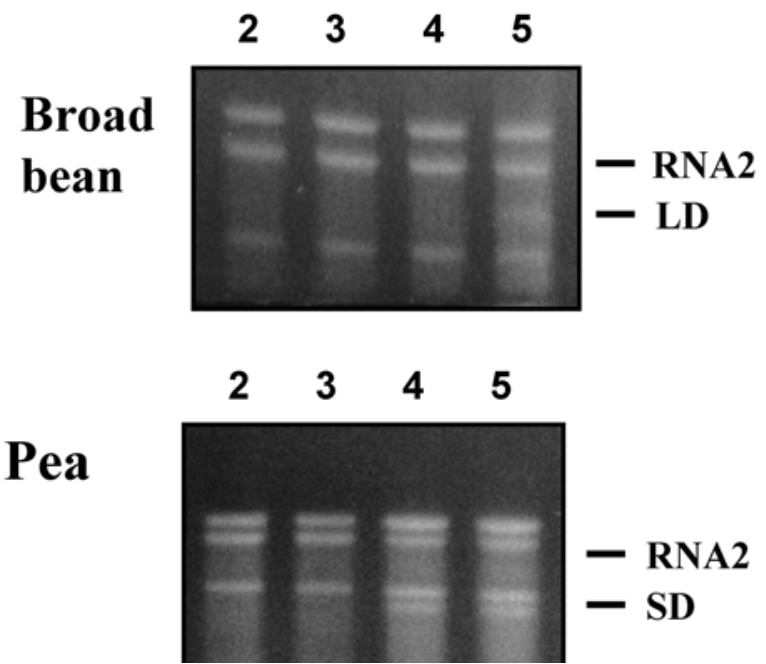

\section{Growth chamber}

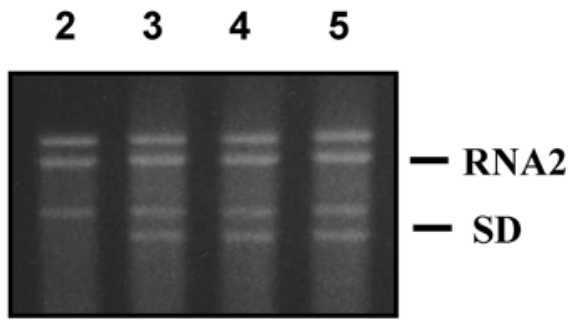

$\begin{array}{llll}2 & 3 & 4 & 5\end{array}$

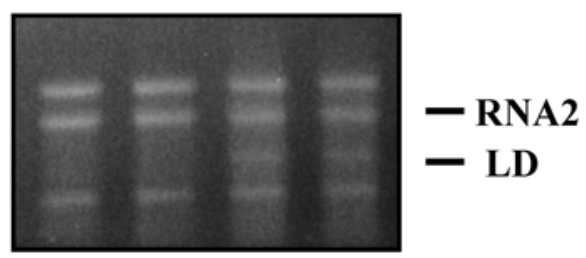

B
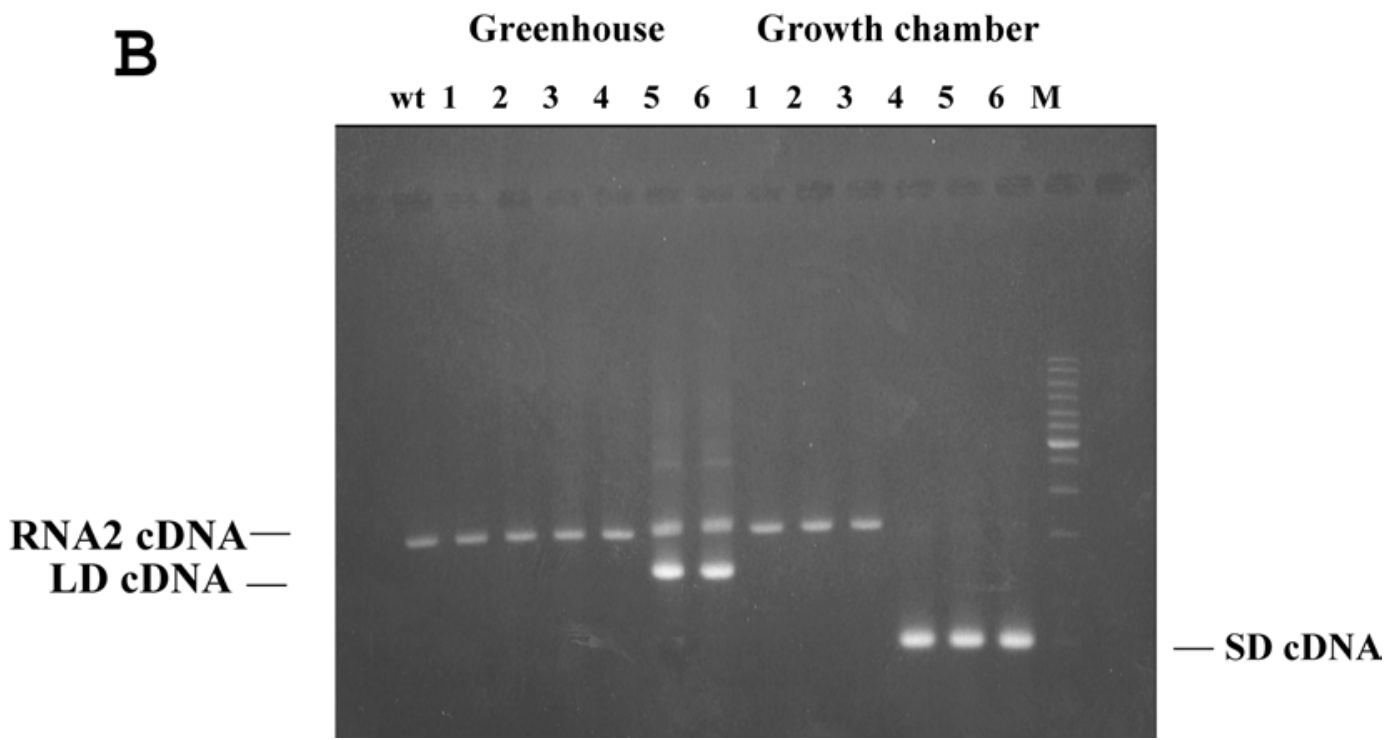

Fig. 3. A, Accumulation of the de novo-generated Broad bean mottle virus (BBMV) defective interfering (DI) RNAs after serial passages in broad bean (upper panel) and pea (lower panel) plants maintained in a greenhouse or growth chamber. Plants were inoculated with the DI RNA-free BBMV RNA and, 10 days after inoculation, the encapsidated BBMV RNA was purified and analyzed by electrophoresis in a denaturing agarose gel. Lanes 2 to 5 indicate the corresponding passages, and LD and SD specify large and small DI RNAs, respectively. B, Accumulation of two kinds of DI RNAs in BBMV-infected pea plants that were maintained in a greenhouse (left half) or growth chamber at $20^{\circ} \mathrm{C}$ with $16 \mathrm{~h}$ of light (right half). Pea seedlings were inoculated with $\mathrm{BBMV}$ RNA free of DI RNAs, virion RNA extracted 15 days later, and amplified by reverse-transcription polymerase chain reaction using RNA 2-specific primers 58 and 170. The virus was passaged after 15 days to a new pea plant. WT, BBMV RNA without DI RNA. Lanes 1 to 6 indicate six passages through a new plant. M, 1-kb ladder LD and SD indicate large and small DI RNAs, respectively. 
in a growth chamber, the SD type of DI RNA accumulated after the third passage (Fig. 3A, lanes 2 to 5, right panel). A reverse trend was observed for the BBMV-infected pea plants (Fig. 3A, lower panels), in which SD RNAs accumulated after the fourth passage in the greenhouse (Fig. 3A, lanes 2 to 5, left panel), while LD RNAs formed after the fourth passage in a growth chamber (Fig. 3A, lanes 2 to 5, right panel).

To further confirm the composition of the DI RNAs accumulating after passages in pea, the plants were inoculated with DI RNA-free BBMV virus preparations, and total RNA preparations were extracted after each passage when grown in the greenhouse or in the growth chamber. The DI RNAs were amplified with RNA 2-specific oligonucleotide primers 58 and 170, and the products cloned. Only the LD RNAs emerged after the fifth passage in a greenhouse and only the SD RNAs emerged after the fourth passage in a growth chamber (Fig. 3B). These results demonstrated the effects of growing conditions on the accumulation of the kinds of DI RNAs in pea and in broad bean.

The above experiments revealed that environment as well as host could influence the size of the de novo-generated DI RNAs. To further address the interplay between host and environment, pea and broad bean plants were cross-inoculated with the viral material derived from broad bean or pea, respectively, and the plants were kept in either the greenhouse or the growth chamber, under the conditions described above. All the primarily inoculated plants accumulated the DI RNAs of the size of those present in the original inoculum (Table 1). However, after the second passage in some combinations, the second kind of DI RNA molecules emerged, of the size expected for the respective hosts under the particular conditions (e.g., broad bean plants grown in greenhouse inoculated with SD). After more passages, only the DI RNA of the size expected for this host was maintained. One exception was that pea plants that were grown in the greenhouse did not accumulate the LD RNAs present in the original inoculum.

Systemic movement and encapsidation of DI RNAs in pea. To analyze systemic movement of DI RNA in pea plants, pea seedlings were inoculated with BBMV inoculum that contained the LD type of DI RNA. After 10 days, a second passage was done through pea plants, using an extract of inoculated or upper leaves from the first passage as inoculum. Total RNA were extracted from infected plants and were analyzed by northern blot hybridization (Fig. 4A). This showed that, after first passage, the LD RNA was accumulating only in the inoculated leaves in two separate inoculation experiments (Fig. 4A, lanes 1 and 2 ' $I$ '). However, after second passage, the LD DI RNA was present in both inoculated and upper noninoculated leaves (Fig. 4A, lanes 1 and 2, 'I' and ' $U$ '). This demonstrated that the initial infection had difficulties in spreading the DI-RNAs systemically, but the next passage increased the DI RNA concentration in systemic leaves.

To determine whether DI RNAs were encapsidated in pea, the virus preparation and then the viral RNA were extracted and analyzed by northern blot hybridization. The LD RNA was not detected in systemically infected upper leaves after two passages
(Fig. 4B, lanes 1 and 2 in the "Passages" section), either in ethidium bromide-stained gels or in northern blots (Fig. 4B, upper and lower panels, respectively). Comparing these results with the data of Figure 4A suggested that the LD RNA was not encapsidated in pea plants.

The accumulation of LD RNA in pea also was confirmed by cloning the RT-PCR products of total RNA preparations from the inoculated leaves (but not from upper leaves, even with symptoms of BBMV infection) of pea seedlings that were infected with the LD RNA-containing BBMV virus (Fig. 4C, compare lanes 'I' and ' $U$ '). Altogether, the data confirmed that environmental conditions and host could strongly affect the size of the accumulating de novo DI RNAs during BBMV infection, and that the LD RNA was not encapsidated in pea.

Sequencing of LD and SD DI RNAs. To determine the location of crossover sites (nucleotides where deletion occurred) and variability within the LD and SD DI RNAs, the RNA preparations were extracted from pea or broad bean leaves, and the DI RNA amplified by RT-PCR and cloned. A restriction analysis of several clones for each cloning experiment demonstrated a homogeneity of DI RNA that accumulated within the particular plant (data not shown). However, a significant variability was observed among plants. Four classes of SD RNAs and five classes of LD RNAs were identified either in pea or in broad bean (Table 2). All were derived by single deletions within a central region of BBMV RNA 2 , but the exact size of the deletion and the positions of junction sites differed. In particular, deletions in the SD type of DI RNAs ranged between 707 and $837 \mathrm{nt}$, whereas those in the LD type ranged between 362 and 537 nt. These results demonstrate a certain degree of randomness during selection of accumulating DI RNAs.

Effect of temperature on the accumulation of BBMV DI RNAs. We studied the effect of temperature on the accumulation of DI RNAs. Pea or broad bean plants were incubated in the chamber at three different temperatures: 20,16 , and $12^{\circ} \mathrm{C}$. The plants were inoculated with BBMV RNA that was free of DI RNA components, and the passages through new plants were done at the same temperature conditions. In broad bean, the SD RNAs were formed at 20 and $16^{\circ} \mathrm{C}$ after three passages (Table 3). However, at $12^{\circ} \mathrm{C}$, the formation of SD RNAs was observed immediately after first passage. Similarly for pea, the LD RNAs accumulated after four passages at $20^{\circ} \mathrm{C}$, after three passages at $16^{\circ} \mathrm{C}$, and after the first passage at $12^{\circ} \mathrm{C}$. In both systems, only one type of DI RNA molecule was observed, and the presence of the DI RNA was easily detectable based on the severity of symptoms.

To test whether the observed effects of temperature were host dependent, the assay was repeated by using two different cultivars of broad bean (cvs. Muchamiel and Aguadulce) and four cultivars of pea (cvs. Lincoln, Froy, Alderman, and Voluntario). The passages were performed at four different temperatures $(24,20$, 16 , and $12^{\circ} \mathrm{C}$ ). For all cultivars tested, the decrease in temperature reduced the number of passages that were required to detect the

TABLE 1. Accumulation of Broad bean mottle virus (BBMV) large (LD) and small (SD) defective interfering (DI) RNAs in pea and broad bean plants after cross-inoculation with the virus from broad bean and pea plants, respectively ${ }^{\mathrm{a}}$

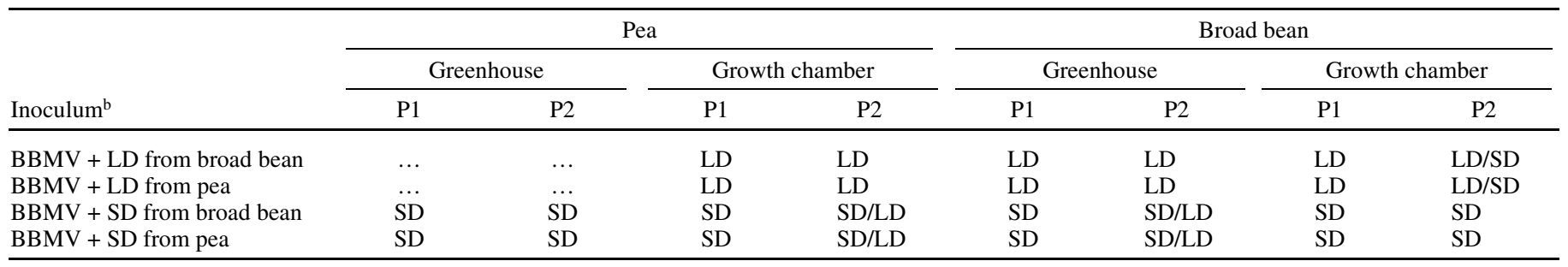

${ }^{a}$ Inoculated plants (P1) were maintained in a greenhouse or in growth chamber; 10 days after inoculation, the virus was passed to the second set of the same plants (P2). The virus and viral RNA were purified and analyzed by electrophoresis in agarose gels or by northern blots; ... not detected.

$\mathrm{b}$ Broad bean (cv. Muchamiel) and pea (cv. Lincoln) seedlings were inoculated with an inoculum derived from leaves of BBMV-infected broad bean and pea plants that carried the LD and SD DI RNAs, respectively. 
accumulation of DI-RNAs (Table 4). In fact, in all cases, the DIRNAs became detectable after one passage at $12^{\circ} \mathrm{C}$. Overall, this demonstrated that the de novo formation or accumulation of BBMV DI RNAs occurred preferably at lower temperatures.

\section{DISCUSSION}

Previous reports have described host effects on the accumulation of DI RNAs $(6,7)$. For instance, Tomato spotted wilt virus (TSWV) accumulated defective RNAs in $N$. benthamiana, pepper, and tomato plants but not in $N$. rustica or Emilia sonchifolia plants $(8,18)$. Also, for Beet curly top virus (BCTV) the accumulation of defective DNAs was high in $N$. benthamiana but less in beet or in tomato (22). However, to our knowledge, there were no data indicating that the host could affect the size of defective RNAs. In this study, we compared the accumulation of DI RNAs in pea and broad bean plants under two sets of conditions. In the growth chamber, the temperature and the light were kept constant; whereas, in the greenhouse, these factors varied with the weather. We found that broad bean plants in the greenhouse and pea plants in the growth chamber accumulated LD DI RNAs, whereas broad bean in the growth chamber and pea in the greenhouse accumulated SD DI RNAs.
To explain these results, one can speculate that the host affects RNA conformation under given environmental conditions, so that certain sites of the parental viral RNAs are exposed for crossover events. Alternatively, certain steps in the virus life cycle or

TABLE 2. The location of crossover sites in small (SD) and large (LD) types of Broad bean mottle virus (BBMV) defective interfering (DI) RNAs from pea or broad bean hosts ${ }^{\mathrm{a}}$

\begin{tabular}{lccl}
\hline Clone & Position of crossovers $^{\mathrm{b}}$ & Size of deletion $^{\mathrm{c}}$ & \\
\hline SD1 & $1,621-2,328$ & 707 & Source \\
SD2 & $1,399-2,236$ & 837 & Pea \\
SD3 & $1,579-2,339$ & 760 & Broad bean, pea \\
SD4 & $1,481-2,224$ & 743 & Broad bean \\
LD1 & $1,660-2,197$ & 537 & Pea \\
LD2 & $1,652-2,176$ & 524 & Pea \\
LD3 & $1,496-1,985$ & 489 & Broad bean \\
LD4 & $1,466-1,846$ & 380 & Pea \\
LD5 & $1,453-1,815$ & 362 & Pea \\
\hline
\end{tabular}

a BBMV DI RNAs, formed de novo in pea or broad bean plants, were amplified by reverse-transcription polymerase chain reaction (RT-PCR) using the RNA 2-specific primers 50 to 170 or 90 to 37 . RT-PCR products were cloned and sequenced.

${ }^{b}$ Numbers indicate the nucleotide positions of the crossover sites.

c Total number of nucleotides deleted.
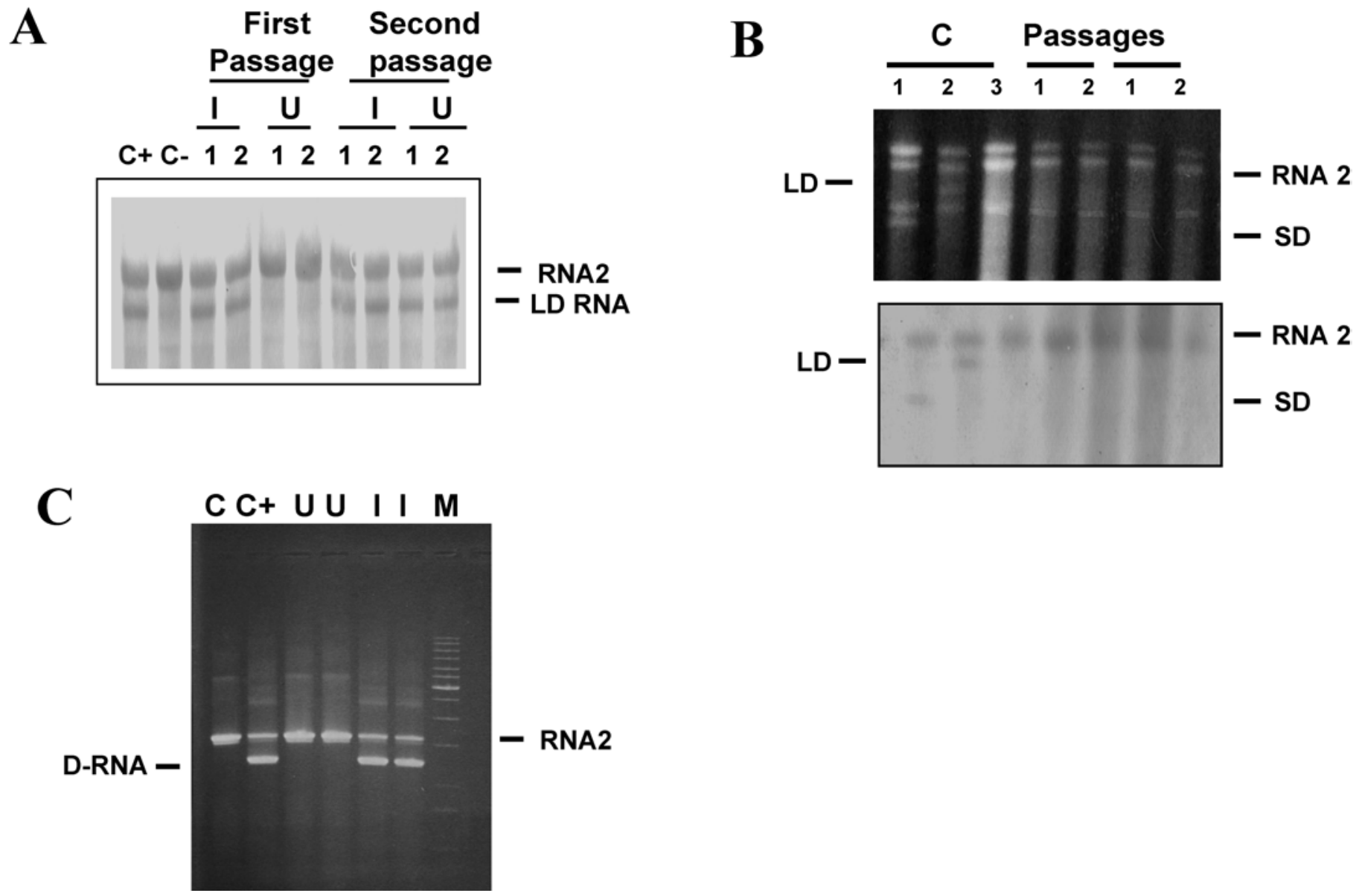

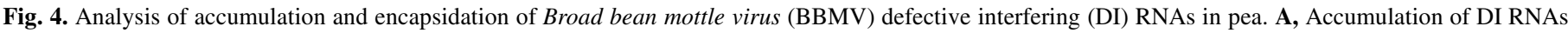

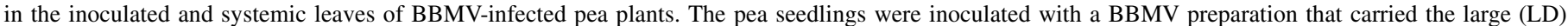

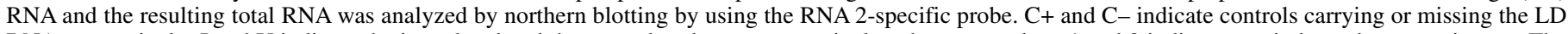

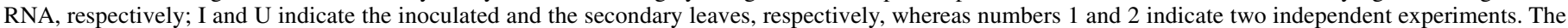

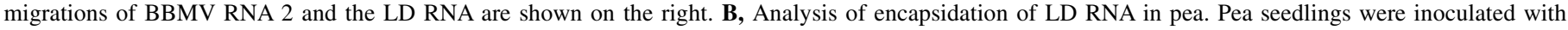

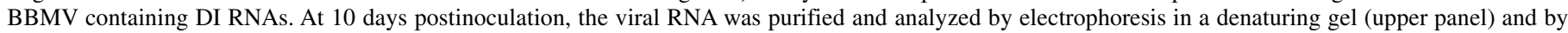

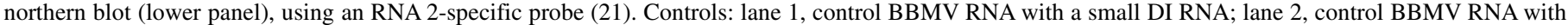

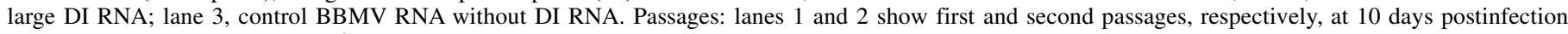

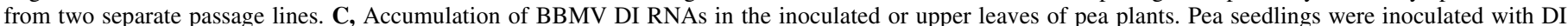

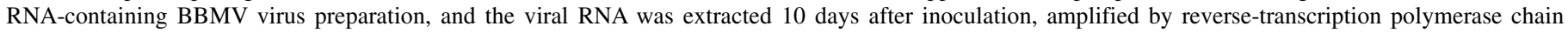

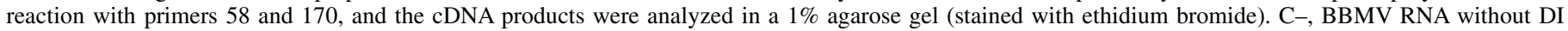
RNAs; C+, BBMV RNA carrying LD DI RNA; I, inoculated leaves; U, upper leaves; M, 1-kb marker. 
TABLE 3. Effect of temperature on the formation of small (SD) and large (LD) defective interfering (DI) RNAs after passages through broad bean or pea plants ${ }^{\mathrm{a}}$

\begin{tabular}{lccccc}
\hline & \multicolumn{2}{c}{ Broad bean } & & \multicolumn{2}{c}{ Pea } \\
\cline { 2 - 3 } \cline { 5 - 6 } Temperature $\left({ }^{\circ} \mathrm{C}\right)$ & Size & Passage & & Size & Passage \\
\hline 20 & SD & 3 & & LD & 4 \\
16 & SD & 3 & & LD & 3 \\
12 & SD & 1 & & LD & 1 \\
\hline
\end{tabular}

a Pea or broad bean seedlings were inoculated with DI RNA-free Broad bean mottle virus and maintained in a growth chamber at different temperatures. At 15 days after inoculation, the virus was passaged on new plants. The virus and its RNA were purified after each passage and analyzed by electrophoresis and in northern blots. Numbers indicate the passage after which the DI RNAs were observed.

changes in physiological conditions of the host can formulate the selection environment. Interestingly, when the virus preparation was derived from one host and then inoculated on the second host (e.g., pea to broad bean), either in the greenhouse or in a growth chamber, initially both DI-RNA types coexisted (the parental one and the one characteristic for the given host). However, after the second passage, the DI RNAs of cognate size predominated and, after more passages, they became exclusive.

The exception to the above trends were pea plants inoculated with BBMV bearing the LD DI RNA and maintained in the greenhouse. In this case, the LD RNA was present only in the inoculated leaves. This could be due to the lack of encapsidation of DI RNAs in pea plants. The requirement of encapsidation for efficient systemic movement was reported in the case of defective RNAs of CYMV and Cymbidium ringspot virus (CymRSV) $(1,24)$. Alternatively, it might reflect the requirement of a host factor, as shown for Cucumber mosaic virus, where the defective RNAs accumulated efficiently in tobacco but did not appear in the upper noninoculated leaves of tomato or cucumber (6). Also, the host mechanisms of the antiviral resistance, such as RNA interference (RNAi), may regulate systemic movement of defective RNAs. In this work, we show that local lesion hosts ( $C$. quinoa, C. Amaranticolor, and C. Murale) do not support the accumulation of BBMV DI RNAs. This could be due to a limited number of replication cycles within local lesions or because of the plant defense mechanisms.

Romero et al. (20) defined hosts that did not support BBMV DI RNA accumulation as "filter" plants. For instance, bean (or pea) plants did not support the accumulation of DI RNAs that predominated in broad bean plants (20). The same effect was observed for Cucumber necrosis virus, where defective RNAs were formed in tobacco plants but were lost after passage through cucumber plants (3). The lack of accumulation of certain types of defective RNAs may not be at the RNA replication level; we observed that BBMV DI RNAs could replicate in bean protoplasts (although to a lower level than in broad bean protoplasts).

That DI RNAs could be formed de novo after several passages through a permissible host has been shown before $(2,10,17)$. We found that, in pea, the DI RNAs can form de novo after passages at a high multiplicity of infection. The formation of DI RNAs while using high-multiplicity passages was demonstrated for TSWV, where a 50-fold dilution of the inoculum permitted the accumulation of DI RNAs, but a 1,000-fold dilution did not (8). It is not known what concentrations of DI RNAs are required in the inoculum for successful transfer to a new host. Law and Morris (13) detected Tomato bushy stunt virus (TBSV) defective RNAs by RT-PCR one passage prior to detection by northern blots. They proposed that defective RNAs replicated at low concentrations but needed a longer period for detectable accumulation.

Our data reveal that the lowering of temperature to $12^{\circ} \mathrm{C}$ clearly improved the formation or accumulation of BBMV DI RNAs, because no passages were required to generate the de novo DI
TABLE 4. Effect of temperature in the formation of large defective interfering (DI) RNAs in different cultivars of pea ${ }^{a}$

\begin{tabular}{lcccc}
\hline & \multicolumn{4}{c}{ Temperature $\left({ }^{\circ} \mathrm{C}\right)$} \\
\cline { 2 - 5 } Cultivar & 24 & 20 & 16 & 12 \\
\hline Froy & 3 & 2 & 2 & 1 \\
Aldermann & 3 & 2 & 2 & 1 \\
Voluntario & 7 & 7 & 5 & 1 \\
Lincoln & 3 & 2 & 2 & 1
\end{tabular}

a Pea seedlings were inoculated with DI RNA-free Broad bean mottle virus and maintained in a growth chamber at different temperatures. At 5 days after inoculation, the virus was passaged on new seedlings. The virus and its RNA were purified after each passage and analyzed by electrophoresis and in northern blots. Numbers indicate the passage after which the DI RNAs were observed.

RNAs in two different hosts. In contrast, five to seven passages required for the formation of BBMV DI RNAs at 16 to $20^{\circ} \mathrm{C}$. We hypothesize that the RNA polymerase is functioning at suboptimal conditions at $12^{\circ} \mathrm{C}$, causing the enzyme to make more errors (i.e., RNA-RNA crossovers) during replication. Also, lower temperatures could preserve secondary structures of virus RNA templates that function as the polymerase pausing sites and thus favor the formation of DI RNAs, change the host defense, or alter selection pressure. Indeed, the facility with which DI RNAs have emerged de novo at low temperatures is, per se, a great methodological improvement with which to study the mechanisms of defective RNA formation during BBMV infection.

Studies of other systems have not always revealed the positive effect of low temperature on DI RNA formation. For instance, Soilborne wheat mosaic virus DI RNAs were detected after several passages at 25 to $30^{\circ} \mathrm{C}$ (4), TBSV formed DI RNAs at $27^{\circ} \mathrm{C}$ but not at $21^{\circ} \mathrm{C}(9)$, and Barley mild mosaic virus DI RNAs were detected at 14 to $16^{\circ} \mathrm{C}$ but not at $10^{\circ} \mathrm{C}$ (23). However, TSWV formed more defective molecules at 16 than at $23^{\circ} \mathrm{C}(8)$. Apparently, a variety of factors can contribute toward the accumulation of DI RNAs during viral infection.

\section{ACKNOWLEDGMENTS}

This work was supported by grants BIO97-0401 and AGL2001-0330 from the Spanish Interministerial Commission for Science and Technology (CICYT) to J. Romero, and by a grant from the National Science Foundation (MCB-9983033) and the Polish Government through a grant (6 P04C 046 19) from the State Committee for Scientific Studies to J. J. Bujarski. S. Llamas and C. Sandoval were supported by fellowships from Instituto Nacional de Investigación y Tecnología Agraria y Alimentaria (INIA) and Agencia Española de Cooperación Internacional (AECI), respectively. We thank K. Makkouk for providing BBMV strains, B. García and F. Sánchez for technical assistance, and S. Castro and J. M. Malpica for comments and discussions.

\section{LITERATURE CITED}

1. Burgyan, J., Dalmay, T., Rubino, L., and Russo, M. 1992. The replication of Cymbidium ringspot tombusvirus defective interfering-satellite RNA hybrid molecules. Virology 190:579-586.

2. Burgyan, J., Rubino, L., and Russo, M. 1991. De novo generation of Cymbidium ringspot virus defective interfering RNA. J. Gen. Virol. 72:505-509.

3. Chang, Y., Borja, M., Scholthof, H. B., Jackson, A. O., and Morris, T. J. 1995. Host effects and sequences essential for accumulation of defective interfering RNAs of cucumber necrosis and tomato bushy stunt tombusviruses. Virology 210:41-53.

4. Chen, J., Macfarlane, S., and Wilson, T. M. A. 1995. An analysis of spontaneous deletion sites in soil-borne wheat mosaic virus RNA2. Virology 209:213-217.

5. Dzianott, M., and Bujarski, J. J. 1991. Nucleotide sequence and genome organization of the RNA-1 segment in two bromovirus: Broad bean mottle virus and cowpea chlorotic mottle virus. Virology 185: 553-562. 
6. Graves, M., Pogany, J., and Romero, J. 1996. Defective interfering RNAs and defective viruses associated with multipartite RNA viruses of plants. Semin. Virol. 7:399-408.

7. Hillman, B., Carrington, J., and Morris, T. J. 1987. A defective interfering RNA that contains a mosaic of a plant virus genome. Cell 51:427-433.

8. Inoue-Nagata, A. K., Kormelink, R., Nagata, T., Kitajima, E. W., Goldbach, R., and Peters, D. 1997. Effects of temperature and host on the generation of tomato spotted wilt virus defective interfering RNAs. Phytopathology 87:1168-1173.

9. Jones, R., Jackson, A., and Morris, T. J. 1990. Defective-interfering RNAs and elevated temperatures inhibit replication of tomato bushy stunt virus in inoculated protoplasts. Virology 150:539-545.

10. Knorr, D., Mullin, R. H., Hearne, P. Q., and Morris, T. J. 1991. De novo generation of defective interfering RNAs of Tomato bushy stunt virus by high multiplicity passage. Virology 181:193-202.

11. Kroner, P., Richards, D., Traynor, P., and Ahlquist, P. 1989. Defined mutations in a small region of brome mosaic virus 2 a gene cause diverse temperature-sensitive RNA replication phenotypes. J. Virol. 63:53025309.

12. Lane, L. 1981. Bromovirus. Pages 333-376 in: Handbook of Plant Virus Infections and Comparative Diagnosis. E. Kurstak, ed. Elsevier/NorthHolland Biomedical Press, Amsterdam.

13. Law, M., and Morris, T. J. 1994. De novo generation and accumulation of tomato stunt virus defective interfering RNAs without serial host passage. Virology 198:377-380.

14. Lazzarini, R. A., Keene, J. D., and Schubert, M. 1981. The origins of defective interfering particles of the negative-strand RNA viruses. Cell 26:145-154.

15. Li, X., and Simon, A. E. 1991. In vivo accumulation of a turnip crinkle virus defective interfering RNA is affected by alterations in size and sequence. J. Virol. 65:4582-4590.

16. Pogany, J., Huang, Q., Romero, J., Nagy, P., and Bujarski, J. J. 1994. Infections transcripts from PCR-amplified broad bean mottle bromo- viruses cDNA clones and variable nature of leader regions in RNA3 segment. J. Gen. Virol. 75:693-699.

17. Pogany, J., Romero, J., Huang, Q., Sgro, J. Y., Shang, H. Z., and Bujarski, J. J. 1995. De novo generation of defective interfering-like RNAs in broad bean mottle bromovirus. Virology 212:574-586.

18. Resende, R., Dehaan, P., Deavila, A. C., Kitajima, E. W., Kormelink, R., Goldbach, R., and Peters, D. 1991. Generation of envelope and defective interfering RNA mutants of Tomato spotted wilt virus by mechanical passage. J. Gen. Virol. 72:2375-2383.

19. Romero, J., Dzianott, A. M., and Bujarski, J. J. 1992. The nucleotide sequence and genome organization of the RNA2 and RNA3 segments in Broad bean mottle virus. Virology 187:671-681.

20. Romero, J., Huang, Q., Pogany, J., and Bujarski, J. J. 1993. Characterization of defective interfering RNA components that increase symptom severity of broad bean mottle virus infections. Virology 194:576-584.

21. Roux, L., Simon, A. E., and Holland, J. J. 1991. Effects of defective interfering viruses on virus replication and pathogenesis in-vitro and invivo. Adv. Virus Res. 40:181-211.

22. Stenger, D. C., Stevenson, M. C., Hormuzdi, S. G., and Bisaro, D. M. 1992. A number of subgenomic DNAs are produced following agroinoculation of plants with beet curly top virus. J. Gen. Virol. 73:237242.

23. Timpe, U., and Kühne, T. 1995. In vitro transcripts of a full-length cDNA of a naturally deleted RNA2 of barley mild mosaic virus (BaMMV) replicate in BaMMV-infected plants. J. Gen. Virol. 76:26192623.

24. White, A., Bancroft, J., and Mackie, G. 1992. Coding capacity determines in vivo accumulation of a defective RNA of clover yellow mosaic virus. J. Virol. 66:3069-3076.

25. White, A., and Morris, T. J. 1994. Recombination between defective tombusvirus RNAs generates functional hybrid genomes. Proc. Natl. Acad. Sci. USA 91:3642-3646. 